Acta Hispanica (2020) Supplementum II: 563-571

\title{
DIÁLOGO JUDEO-CRISTIANO EN LA OBRA DE HUGO SCHLESINGER (1920-1996)*
}

\author{
ANDrzej Pietrzak \\ Universidad Católica Juan Pablo II de Lublin
}

Resumen: Hugo Schlesinger, judío polaco y sobreviviente de holocausto, después de la Segunda Guerra Mundial emigró a Brasil. Dejó un legado significativo de publicaciones dedicadas al tema de economía y comercio, judaísmo, diálogo, desarrollo personal y espiritual. El artículo introduce su pensamiento a través del tema de diálogo judeo-cristiano. La primera parte trata de la experiencia personal de guerra y holocausto, antisemitismo, ideologemas antisemitas, fanatismo y racismo. La segunda se refiere al diálogo y asuntos afines como comprensión del judaísmo, presencia e integración de judíos en la sociedad, Justos entre las Naciones y Consejo de Fraternidad Cristiano-Judaica en Brasil.

Palabras clave: judaísmo, judíos polacos, diálogo judeo-cristiano, judíos en Brasil, Consejo de Fraternidad Cristiano-Judaica.

Abstract: Hugo Schlesinger, a Polish Jew and Holocaust survivor, after World War II emigrated to Brazil. He left a significant legacy of publications dedicated to the topic of economics and commerce, Judaism, dialogue, personal and spiritual development. The article introduces his thinking through the theme of Judeo-Christian dialogue. The first part deals with personal experience of war and holocaust, anti-Semitism, anti-Semitic ideologems, fanaticism and racism. The second refers to dialogue and related matters such as understanding of Judaism, presence and integration of Jews in society, Righteous Among the Nations and the Christian-Judaic Fraternity Council in Brazil.

Keywords: Judaism, Polish Jews, Judeo-Christian Dialogue, Jews in Brazil, Christian-Jewish Brotherhood Council.

Hugo Schlesinger, nacido en Bielsko-Biała (Polonia), pertenece a ese grupo de judíos polacos que, durante los atroces años de la Segunda Guerra Mundial, buscaban refugio y ayuda en varios países europeos. Cuando llegó la ocasión favorable integró, como soldado al ejército polaco del general Władysław Anders en la campaña militar en Italia contra la Alemania nazi, por el cual recibió la condecoración militar "Estrella de Italia" y "Medalla del ejército polaco por la guerra de 1939-45". Terminada la guerra, en 1946 se estableció en Brasil, donde actuó como periodista, cineasta, economista, profesor y orador.

\footnotetext{
${ }^{*}$ The project is funded by the Minister of Science and Higher Education within the program under the name "Regional Initiative of Excellence" in 2019-2022, project number: 028/RID/2018/19, the amount of funding: 11742500 PLN.
}

Acta Hispanica, Hungría, Supplementum II: 563-571, 2020, ISSN: 1416-7263 | 563 
En la nueva realidad sociocultural y religiosa, Schlesinger desempeñó un papel positivo de persona que promovía acercamiento y creaba lazos entre personas y comunidades, como divulgador de conocimiento sobre judaísmo y animador de diálogo interreligioso. Él dejó un legado significativo de publicaciones (Pietrzak, 2017: 173-183). Una parte de ellas está dedicada al tema de diálogo, judaísmo, desarrollo personal y espiritual. Consciente de que los judíos y los cristianos tienen una larga historia de relaciones de crecimiento recíproco, al mismo tiempo difíciles y trágicas, con empatía y asertividad, valentía y determinación optaba por la divulgación del diálogo y acercamiento. Aquí prestaremos atención a dos cuestiones claves relacionadas con el diálogo en su obra.

\section{Shoah y antisemitismo}

La obra de Schlesinger, respectiva al tema de diálogo entre judaísmo y cristianismo (catolicismo), está marcada, en una gran parte, por la aterradora experiencia del holocausto. La comunidad judía en Alemania, desde 1933, vivió la tragedia de la persecución sistemática de la máquina estatal nazi. Desde mediados de 1941, preparada la solución final de la cuestión judía (Endlösung der Judenfrage), a partir de la conferencia de Wannsee (20 de enero de 1942) envolvió los departamentos gubernamentales del Tercer Reich necesarios para ese cruel plan a ser cumplido en los países bajo la ocupación alemana. Utilizando los tradicionales métodos de aniquilación y los modernos logros de la ciencia y tecnología, se asesinaron a unos 6 millones de judíos en los campos de exterminio y otros lugares de martirio. A este facto Schlesinger se refiere a menudo (Schlesinger, 1978; 1987a; 1990; Schlesinger - Porto, 1975). Años después, ya en Brasil, escribía que entonces "La bestialidad humana ha cruzado el límite de la crueldad y de la infamia en esta era de terror y miedo" (Schlesinger, 1987a: 7).

La actitud de Schlesinger hacia el diálogo circunscribe también el problema de antisemitismo en la historia. A menudo discute el fenómeno y sus diversos aspectos. Introducida en 1879 por Wilhelm Marr la palabra "antisemitismo", a pesar de inexactitudes etimológicas, recuerda Schlesinger, no significa un simple prejuicio social que pueda eliminarse mediante diálogo ordinario o educación. El antisemitismo es "una pasión odiosa, similar a la xenofobia, incluso más mordaz, más cercana al racismo feroz porque se centra en los judíos y solo en ellos" (Schlesinger - Porto, 1975: 29). Un antisemita, por otro lado, es una persona que:

[...] sin una evaluación crítica previa reconoce su forma de pensar y aplica una serie de suposiciones completamente infundadas sobre la vida y la personalidad de judíos. En la mayoría de los casos, solo repite lo que ha escuchado y está actuando mecánicamente como otros, permitiéndose quedar atrapado en los mecanismos psicológicos incontrolables del prejuicio social (Schlesinger - Porto, 1975: 29). 
Por lo tanto, el antisemitismo funciona en el espacio de estereotipos, pero va más allá. Los hombres, operando dentro de sus ideologías y cosmovisiones (Zemszał, 2008: 8387; 2014: 46-56; Domańska, 2001: 37-60) tienen la tendencia de contrastar personas y estigmatizarlas. Consecuentemente el antisemitismo aparece en la historia como aversión a los judíos, hostilidad y odio hacia su pueblo. En forma fanática se convierte, a veces, en sangrienta persecución. El antisemitismo puede surgir de orgullo o prejuicio nacionalista y aristocrático, de intento de eliminar competidores, de vanidad personal y manía verbal incorregible (Schlesinger - Porto, 1975: 18).

$\mathrm{El}$ antisemitismo busca justificar teóricamente sus afirmaciones, actitudes y acciones. Aunque es una doctrina compleja, Schlesinger distingue cuatro componentes. Primero, el punto de partida del antisemitismo es una opinión subjetiva sobre los judíos, desprovista de cualquier fundamento real o justificación lógica. En segundo lugar, el antisemitismo se caracteriza por una ardiente sumisión a impulsos ciegos de gran poder destructivo e impredecible. Tercero, el antisemitismo se alimenta de un tipo de neurosis fóbica en la que el mismo objeto se convierte en objeto de agresión y destrucción. Por último, el antisemitismo manifiesta síntomas del maniqueísmo social (Schlesinger Porto, 1975: 20-27).

Al analizar el antisemitismo, Schlesinger va más allá de la clara presentación de discursos antisemitas individuales y colectivos, acciones institucionales contra los judíos en la historia (Schlesinger, 1975: 89-298; Schlesinger - Porto, 1975). Para comprender la violencia y la exclusión aplicadas a esta comunidad, utiliza la psicología y la sociología del comportamiento humano. Las teorías psicoanalíticas dan una posible explicación de las fuentes, principios y mecanismos del antisemitismo. Nos permiten comprender que él está integrado en los problemas polifacéticos de la vida individual, comunitaria y social. Se nutre de fenómeno generalizado de injusticia, especialmente en orden estructural. Al ganar el impulso y apoyo en la historia, se traduce en proyectos conscientes impregnados de prejuicios antijudíos en el área legislativa, estructural y sistémica. Vive y se propaga gracias a acciones intencionales y manipulaciones de líderes políticos y religiosos (Schlesinger - Porto, 1975: 28).

Los procesos psicológicos relacionados con seguridad, alteridad, ansiedad y hostilidad juegan un papel específico en la génesis de prejuicios antisemitas. La psicología moderna es unánime a este respecto, dice Schlesinger. Para fortalecer esa tesis evoca las opiniones de G. Allport (1964) y H. G. Gough (1953), partidarios de la teoría de relación precisa entre prejuicios y experiencia de incertidumbre (amenaza), tanto de individuos como de grupos. La convergencia de varios factores psicológicos y sociales puede conducir al surgimiento de la personalidad antisemita. El entorno familiar y demás experiencias de individuo y su comunidad juegan un papel tajante en su configuración (Schlesinger Porto, 1975: 28-45).

Este fenómeno no solo afecta a las personas. La historia confirma que sociedades o sus sectores pueden mostrar intolerancia y agresión hacia los judíos. El origen de tal fenómeno no debe buscarse solo en la suma de las características antisemitas de 
individuos. Según Schlesinger, la respuesta a la pregunta sobre la génesis de tal antisemitismo "socializado" se encuentra en dos fenómenos: en la tendencia común a difundir infecciosamente ideas-juicios acríticos y en el fenómeno de integrarlos en los esquemas psicológicos del grupo (Schlesinger - Porto, 1975: 45-47).

Schlesinger explica que, hasta la Revolución Francesa, el rechazo y las actitudes hostiles hacia los judíos derivan de algunas formas de premisas teológicas o intereses políticos, pero sin justificaciones sistémicas, filosóficas y existenciales. El proceso de creación de fundamentos ideológicos del antisemitismo comenzó con esta revolución. Teniendo en cuenta la historia del odio hacia los judíos, se puede recrear un esquema de dicha ideología, aunque no esté exento de limitaciones. El antisemitismo, como cualquier ideología, siempre implicará:

a) visión general del mundo;

b) relación con grupo social específico;

c) consecuencias prácticas y sociales (no es una teoría solamente);

d) metas sociopolíticas variables;

e) relación entre valores (axiología) y objetivos sociopolíticos como formas de realización de destino último del hombre.

La pasión antisemita, afirma Schlesinger, cumple todos estos requisitos. En los tiempos modernos, hacía bruscamente parte de la crítica de los sistemas sociales comunismo, fascismo y nazismo- y de sus proyectos radicales de implantar nueva sociedad. Indiferentes al costo, ambicionaban crear al hombre nuevo y aniquilaban a todo y todos que no encajaban en estos proyectos (Schlesinger - Porto, 1975: 78-81).

En el análisis del fenómeno del antisemitismo, Schlesinger usa la categoría de "ideologema”. Según él, aquí se trata de pequeñas unidades semánticas representativas del lenguaje, que portan creencias reconocidas y populares de grupo. Entretanto, ellas no representan conocimiento en sentido de episteme, sino doxa platónico - información falsa, no probada. Desde un punto de vista psicológico, los ideologemas, también antisemitas, se originan en la tendencia de percibir selectivamente a personas de cultura, etnia y religión diferentes. Señala que, en las sociedades actuales, los ideologemas populares sobre el antisemitismo están asociados a la percepción cristiana de judíos (Schlesinger Porto, 1975: 83).

Los ideologemas, dice Schlesinger, germinan en el contexto de acusaciones de presunta apropiación, indebida por parte de judíos y judaísmo, de leyes morales y fe en Dios. Por lo tanto, su imagen social es selectiva, parcial y falsa. Fortalece despersonificación de judíos, resentimiento y hostilidad hacia ellos. Ideológicamente apoyan modelos de comportamiento práctico, planes de acción y narrativa, que los justifique. Esta ilusoria e interesante percepción está marcada por experiencias selectivas del grupo hacia el cual se tiene prejuicio. Primeros rastros de ideologemas están en la obra "Contra Apión" de Flavio Josefo. Diseminados y creados nuevos, descartan por defecto, el derecho y deseo de judíos de aceptación como personas, enfatiza Schlesinger. Cualquier generalización, incluso creada 
de buena fe, conlleva una deformación de la realidad, profundiza y prepara un espacio para antisemitismo (Schlesinger - Porto, 1975: 83-87).

Schlesinger observaba también la historia de los judíos. Sintetizándola con la experiencia personal en su tierra natal (Polonia) y otros países europeos, escribía:

Quién conoce el martirio del pueblo judío a lo largo de los siglos y recuerda las acusaciones de deicidio, las mentiras del asesinato ritual, la calumnia de la profanación del anfitrión, las consecuencias de la insignia amarilla, las masacres durante las cruzadas, las disputas religiosas, las tragedias de la Inquisición, las diversas bulas papales contra los judíos, la quema del Talmud, los pogromos en los países eslavos, los guetos, los campos de exterminio, los hornos crematorios - difícilmente podría creer o imaginar que estos momentos de oscuridad, falta del razonamiento y la ausencia de sentimientos humanos algún día podrían llegar a su fin (Schlesinger, 1987a: 1).

$\mathrm{El}$ antisemitismo es una constante en la historia. En el pasado se nota una simetría aterradora, según Schlesinger. En todos los lugares donde los judíos buscaban un lugar para vivir, con tiempo, presenciaran el nacimiento y el desarrollo del odio antisemita en tres formas principales:

a) religioso - particular en los tiempos feudales, después del año 873;

b) económico, por ejemplo, durante la Revolución Francesa (1978-1799);

c) institucional, luego del anuncio "La victoria del judaísmo sobre el germanismo" de Wilhem Marr.

Con frecuencia asociadas a tendencias imperialistas de grupos políticos, económicos y religiosos, creaban destino doloroso y sanguinolento para la comunidad judía. La Biblia y las fuentes históricas de diferentes épocas evidencian numerosos hechos antisemitas (Schlesinger - Porto, 1975: 92).

\section{Diálogo y vida sin prejuicios}

En la obra literaria y la actividad social de Schlesinger llama atención laboriosidad a favor de la paz, la libertad y la hermandad. En el libro dedicado al itinerario de su vida explica:

Quien nació y vivió su juventud, como yo, en un país muy intolerante donde se sentían prejuicios religiosos a cada paso, siempre anheló una libertad religiosa y soñó con la comprensión y la hermandad entre los hombres. Cuando durante la Segunda Guerra Mundial encontré en Italia sentimientos y comportamientos muy diferentes y personas más humanas, comencé a creer que estos sueños míos algún día podrían hacerse realidad. La ayuda voluntaria y espontánea a los perseguidos y la preocupación por salvar a los 
Diálogo judeo-cristiano en la obra de Hugo Schlesinger (1920-1996)

inocentes me dieron el ímpetu para aliarme con aquellos que sabían cómo honrar a la raza humana. Me convencí cada vez más de que aquellos que arriesgaban sus vidas por la vida de los demás deberían ser recordados con profundo respeto (Schlesinger, 1987a: 9).

Esta confesión-plan de vida se traduce en años de su presencia y dedicación a la problemática del acercamiento interreligioso, construcción de puentes entre la gente y apoyo de la gente en el crecimiento personal.

Según Schlesinger, el diálogo es necesario porque lo requieren las víctimas inocentes de las persecuciones antisemitas de todos los tiempos. Además, difícilmente podrá ser callado el eco de llanto y desespero de los mártires del holocausto. En el diálogo, por tanto, debe ser oída la verdad sobre los hechos inhumanos y crueles que decimaron y marginaron al pueblo judío. Aquí, no se trata de venganza o blancos políticos, pero de fundamental derecho a la memoria y verdad. Perdón, importante en el diálogo, hace parte de filosofía de vida del judaísmo. Sin él, la vida y la convivencia humana son insostenibles (Schlesinger, 1987a: 2).

En la Biblia, el libro básico para los judíos y cristianos, encontramos fundamentos y motivación para el diálogo. Ella nos enseña el amor al próximo y réproba el odio: "No guardarás odio a tu hermano en tu corazón" (Lev 19,17). La argumentación a favor del diálogo Schlesinger encuentra también en la sabiduría de los filósofos judíos y en el Talmud. En sus enseñanzas se valoriza la vida en paz y la harmonía con los demás. Lo que tenemos que odiar, dice, son la falsedad, la violencia y el egoísmo. El odio destruye la vida social. Odiar a una persona, también a nuestros enemigos, significa odiar a su Creador. El hombre tiene lugar especial en la creación. Su dignidad y grandeza son independientes de las hermenéuticas que introducen divisiones por países, razas o credos religiosos. Hechos por el mismo Creador, afirma Schlesinger, todos somos iguales y hermanos. En la tradición judaica el amor por todos los pueblos es un valor fundamental y orientado del diálogo (Schlesinger, 1987a: 2).

La necesidad del diálogo brota de la convicción de que cada persona o grupo tiene algo vital para ofrecer a los demás. El diálogo significa encontrarse en el espacio y tiempo definidos, presencia y acercamiento, abertura fundamental al otro e inteligente coloquio. Él es posible porque los seres humanos necesitamos abrir nuestras mentes, escuchar al otro, entender lo que intenta decir. Además, el diálogo es fundamental para nuestro desarrollo individual y colectivo. La historia humana evidenció innúmeras veces que el aislamiento y sus justificaciones preparan estancamiento, regresión y conflictos criminosos (Schlesinger, 1987a: 2).

Schlesinger declara que el antisemitismo no desaparecerá debido a sus profundas raíces en la naturaleza humana (el odio, p. ej.). Entretanto, podemos pronosticar que el antisemitismo disminuya en el futuro. No obstante, sus posibles regresos en mayor o mayor medida, muy probablemente el progreso civilizatorio eliminará la barbaridad, el odio y el prejuicio que los acompañan en la escala que había ocurrido en el pasado. Por lo tanto, el diálogo es necesario para minimizar los efectos no solo del antisemitismo, 
sino también de las tendencias negativas en la naturaleza humana. Él crea oportunidades para superar el antisemitismo religioso y teológico, que es autor, propagador y fijador principal de la actitud negativa hacia los judíos (Schlesinger, 1987a: 183-186).

El análisis de la vida y obra literaria de Schlesinger autoriza la siguiente conclusión: la mayoría de sus obras tiene función dialógica. Los problemas que aborda no son accidentales. Este es el caso, por ejemplo, de libros que hablan del judaísmo (Schlesinger, 1969; 1992), religiones (Schlesinger - Porto, 1986; 1988) y orígenes judíos del cristianismo o escritos que enriquecen su comprensión (Schlesinger - Porto 1975; Schlesinger, 1971; 1973). Otra parte de sus escritos presenta la contribución de los judíos al desarrollo cultural, científico, filosófico, económico y político de Brasil y del mundo. Estos demuestran y proponen un sustancial modelo de presencia e integración de judíos en la sociedad (Schlesinger, 1982; 1987b). Además, Schlesinger dedicó un espacio en su obra para las personas que ayudaban a los judíos durante la shoah, salvando sus vidas (Schlesinger, 1978).

Finalmente, tenemos que recordar que Schlesinger era un hombre que realizaba el diálogo en su vida. Dirigía cursos y conferencias y ocupaba la decimoctava silla de la Academia Cristiana de Letras. Fue miembro y copresidente del Consejo de Fraternidad Cristiano-Judía en Brasil. Schlesinger decía sobre esta institución:

El Consejo de Fraternidad Cristiana-Judía es una entidad compuesta por personas dispuestas a tomar en serio las demandas de unidad y fraternidad universal, rechazando todo tipo de discriminación étnica y religiosa. Es una experiencia de alto nivel de comunión humana. Es una convivencia en atmósfera de diálogo existencial, de respeto y amor mutuos, de personas de diferentes creencias religiosas que convergen en los mismos ideales superiores de comprensión y tolerancia, justicia y libertad, solidaridad y paz (Schlesinger, 1987: 36).

Sin duda ella era un capítulo importante en la historia del diálogo cristiano-judío en América Latina. Llevó a cabo una misión única de reunir a las personas que deseaban un clima fraternal de paz y justicia.

\section{Conclusión}

El legado literario de Schlesinger permite identificar temas valiosos para las relaciones judeo-cristianas. En sus obras se nota un tipo de angustia humana positiva. Él actuaba y escribía textos donde se nota el sincero deseo de "encontrar formas y soluciones para problemas que aparentemente no tienen solución” (Schlesinger, 1987a: 1). El origen de esa actitud se debe buscar en su formación humana y religiosa, como también en la experiencia personal, particularmente en la manera de ver e interpretar la vida. Consecuentemente, no será arbitrariedad decir que el tiempo de infancia y adolescencia en Polonia, la shoab y los años de la guerra, hayan marcado al joven Hugo, su itinerario, 
sus escritos y sus actividades posteriores. Este factor básico ha llevado a Schlesinger a la actividad social como promotor del diálogo y miembro activo de iniciativas e instituciones que apoyaban el acercamiento de personas procedentes de diferentes países, culturas, religiones y grupos étnicos. Esto, a su vez, orientó la investigación histórica y la búsqueda de modelos interpretativos. Schlesinger era un hombre del renacimiento, talentoso, de clara identidad y religiosidad. Era una persona positiva y abierta, anhelaba un mundo mejor. Dejó un legado válido para nuestros días: un testimonio vivo de actividad positiva y constructiva entre personas que, a pesar de sus particularidades y diferencias culturales luchan y trabajan juntos, promueven valores humanos, se respaldan en el destino común de la humanidad.

\section{Referencias bibliográficas}

Allport, Gordon (1964). The Nature of Prejudice. Massachusetts: Cambrige University Press. Domańska, Ewa (2001). Ku archeontologii martwego ciała: kontemplacyjne podejście do przeszłości, ER(R)GO. Teoria-Literatura-Kultura, 2(3). 37-60.

Gough, Harrison G. (1951) Studies of Social Intolerance: IV. Related Social Attitudes. The Journal of Social Psychology, 33/2. 263-269.

Pietrzak, Andrzej (2017). Hugo Schlesinger (1920-1996). Promotor kultury i dialogu żydowsko-chrześcijańskiego w Brazylii. En: Ryszard Zajączkowski (ed.). 2017. Literatura polska na obczyźnie - zapomniane dĩedzictwo po roku 1939. Lublin: TNKUL. 173-183.

Schlesinger, Hugo (1992). Por livre e espontânea vontade. Rio de Janeiro: Imago Editora.

Shlesinger, Hugo (1990). O último papa. Rio de Janeiro: Imago Editiora.

Schlesinger, Hugo (1987a). Um diálogo sem preconceitos. São Paulo: Conselho de Fraternidade Cristão-Judaica.

Schlesinger, Hugo (1987b). Médicos Judeus na História da Medicina. São Paulo: Organização Andrei Editora LTDA.

Schlesinger, Hugo (1982). Meus irmãos famosos. Judeus de ontem e hoje a serviço da bumanidade. São Paulo: Editora B'nai B'rith.

Schlesinger, Hugo (1978). O testemunho dos justos, Sobreviventes do massacre nazista contam suas histórias. São Paulo: Edições Paulinas.

Schlesinger, Hugo (1973). Os papas e os judeus. Petrópolis: Vozes.

Schlesinger, Hugo (1971). Raízes e origens judaicas do cristianismo. São Paulo: Editora B'nai B'rith.

Schlesinger, Hugo (1969). Pequeno ABC do pensamento judaico. Sintese de definições dos valores religiosos, morais e éticos do judaísmo. São Paulo: Editora B'nai B'rith. 
Andrzej Pietrzak

Schlesinger, Hugo - Porto, Humberto (1988). Geografia universal das religiões. São Paulo: Edições Paulinas.

Schlesinger, Hugo - Porto, Humberto (1986). Líderes religiosos da humanidade. Vol. 1-2. São Paulo: Edições Paulinas.

Schlesinger, Hugo - Porto, Humberto (1975). Anatomia do anti-semitismo. São Paulo: Edições Loyola.

Zemszal, Piotr (2014). Wartościowanie uniwersalne i ideologiczne - pojęcie i rola ideologemu na przykładzie wybranych nominacji dotyczących Stalina w sowieckim dyskursie ideologicznym, Etnolingwistyka, 26. 46-56.

Zemszał, Piotr (2008). Ideologem w dyskursie ideologicznym, Oblicza Komunikacji, 1. 83-87. 